\title{
CARACTERIZAÇÃo E HIDRÓlise in vitro DA GLOBULINA PRINCIPAL DE GRÃO-DE-BICO (Cicer arietinum L.), var. IAC-Marrocos ${ }^{1}$
}

\author{
Valdir A. NEVES ${ }^{2, *}$, Maraiza A. da SILVA², Euclides J. LOURENÇO ${ }^{3}$
}

\begin{abstract}
RESUMO
No presente estudo procedeu-se ao isolamento e caracterização da fração globulina majoritária (11 S) de grão-de-bico, var. IACMarrocos. A globulina majoritária extraída foi isolada por cromatografia de filtração em gel e de troca-iônica mostrando apenas uma banda de proteína na eletroforese em gel de poliacrilamida. A globulina majoritária, após passagem em coluna de Sephadex, revelou duas bandas protéicas de 55 e $52,5 \mathrm{kDa}$ e três bandas menores em gel de poliacrilamida dodecilsulfato de sódio. Na presença de 2-mercaptoetanol 6 polipeptídios na faixa de 18 a $42 \mathrm{kDa}$ foram revelados na eletroforese. A globulina isolada foi submetida à ação da tripsina e quimotripsina onde a forma nativa mostrou-se resistente à ação enzimática enquanto o aquecimento $\left(96\right.$ e $121^{\circ} \mathrm{C} /$ $15 \mathrm{~min}$ ) não foi suficiente para aumentar a susceptibilidade à hidrólise, significativamente. Adição de $\mathrm{NaCl} 0,3 \mathrm{M}$ levou a um aumento da estabilidade estrutural com menor susceptibilidade à digestão proteolítica, fato em parte perdido com o aquecimento. As hidrólises foram acompanhadas por eletroforese em gel de poliacrilamida dodecilsulfato de sódio.

Palavras-chave: grão-de-bico; Cicer arietinum L.; globulina majoritária; caracterização; hidrólise in vitro.
\end{abstract}

\section{SUMMARY}

CHARACTERIZATION AND in vitro TRYPTIC HYDROLYSIS OF THE MAJOR GLOBULIN FROM CHICKPEA (Cicer arietinum L.). The isolation and characterization of the major globulin fraction (11 S) from Chickpea, vc IAC-Marrocos, were evaluated. The major globulin was extracted, isolated by gel filtration and ion-exchange chromatography showing only one protein band on PAGE. The globulin, after Sephadex elution, revealed two protein bands of 55 and $52.5 \mathrm{kDa}$ and three minor bands on SDS-PAGE. In the presence of 2-mercaptoethanol six polypeptides were revealed on SDS-PAGE in the range of 18 to $42 \mathrm{kDa}$. The isolated native globulin shown to be resistant to trypsin and chymotrypsin however heating at 96 and $121^{\circ} \mathrm{C} / 15 \mathrm{~min}$ was not sufficient to increase the hydrolysis significantly. The proteolytic susceptibility of the enzymes was reduced by $0.3 \mathrm{M} \mathrm{NaCl}$ addition at the assay. The salt concentration was sufficient to stabilize the native protein structure that was lost after heating as demonstrated on SDS-PAGE. Keywords: chickpea; Cicer arietinum L.; major globulin; characterization; in vitro hydrolysis.

\section{1 - INTRODUÇÃO}

As sementes de leguminosas caracterizam-se por apresentarem alto teor protéico, 12 a 35\%, com algumas variedades de soja alcançando 40 e até $50 \%$ de proteína na semente $[9,13,26]$. Globulinas e albuminas correspondem a $80 \%$ da proteína total sendo que as diferentes proporções dessas entre espécies e variedades de leguminosas, de certa forma, explicam as distintas propriedades funcionais e também refletindo na qualidade nutricional.

O predomínio da fração globulina tem despertado crescente interesse pelo isolamento e caracterização dessa fração em diferentes gêneros e espécies, destacando-se Vicia faba [40], Pisum sativum [19], Glycine max [21] e Phaseolus [8, 38], entre outros [13]. Características distintas de solubilidade em sal, coeficiente de sedimentação em ultracentrífuga e peso molecular tem revelado a presença de duas frações globulínicas majoritárias, onde na grande maioria dos gêneros parece

\footnotetext{
1. Recebido para publicação em 05/05/2003. Aceito para publicação em 01/12/2003 (001122).

2. Departamento de Alimentos e Nutrição. Faculdade de Ciências Farmacêuticas - Universidade Paulista "Julio de Mesquita Filho"-UNESP. Rodovia Araraquara-Jaú Km 1. CEP 14801-902 - Araraquara - S.P. Email: nevesva@fcfar.unesp.br.

3. Faculdade de Ciências, Fundação Educacional de Barretos, Barretos, São Paulo-Brasil.

*A quem a correspondência deve ser enviada.
}

predominar a fração 11S (tipo legumina), enquanto no Phaseolus a 7S (tipo vicilina) é a fração principal [13].

A baixa digestibilidade da proteína de leguminosas parece resultar de diversas causas, porém, sem uma única explicação definitiva, e tem sido associada a interações proteína-tanino da semente [28], complexos proteína-fitato [10], proteína-fibra [26], inibição de enzimas digestivas [15], constrangimentos estruturais [14, 32] e estrutura compacta de sua fração majoritária [1, 29], as globulinas; presença de açúcares ligados à estrutura das globulinas e albuminas e possiveis impedimentos estéricos à ação das enzimas [30], além de interações proteína-proteína e proteína-carboidratos no tratamento térmico e interações proteína-outros constituintes no aquecimento. A digestibilidade in vitro da proteína total de grão-de-bico, em diferentes genótipos, mostra uma variação entre 60,4 e $74,4 \%$ [2, 11], e aumento variável de 68,6 a $77,5 \%$ foi observado em diferentes cultivares após descorticação e/ou cozimento $[4,7,20]$. Essa digestibilidade protéica tem sido melhorada em função de tratamentos, tais como: germinação, fermentação, aquecimento, descorticação, entre outros [9, 27]. A germinação e fermentação de grão-de-bico provocaram aumento da digestibilidade in vitro em grau superior ao observado pós autoclavagem [10]. Por outro lado, o grão-de-bico apresenta baixos níveis de compostos polifenólicos [9, 36], enquanto os inibidores de proteases são facilmente destruídos pelos procedimentos normais de cozimento [9], e em alguns casos, tem se verificado correlação negativa entre atividade de inibidor de tripsina e a digestibilidade in 
vitro, pós-aquecimento [34]. Enquanto a estrutura compacta da fração globulina majoritária de certas espécies, tais como o feijão (7S) e soja (11S), têm sido associada a sua menor susceptibilidade à proteólise in vitro, com reflexos na digestibilidade, não há registros na literatura sobre o papel das diferentes frações globulínicas do grão-de-bico na reduzida digestibilidade de sua proteína [9, 11, 36]. Nesse sentido, estudos de isolamento, caracterização e hidrólise proteolítica destas frações em diferentes espécies se faz necessário para fundamentação dos estudos básicos e aplicados sobre proteínas de sementes. O intuito de contribuir para reduzir esta lacuna é um dos objetivos das propostas desse trabalho, quer seja: isolar, purificar a fração globulina principal do grão-de-bico e determinar o efeito da ação de enzimas proteolíticas na estabilidade de sua estrutura através da proteólise in vitro.

\section{2 - MATERIAL E MÉTODOS}

\section{1 - Material}

Globulina principal do grão-de-bico (Cicer arietinum L.), cultivar IAC-Marrocos, isolada e purificada em coluna de Sepharose CL-6B, conforme procedimento descrito por KUMAR \& VENKATARAMAN [23] e SILVA, NEVES \& LOURENÇO [35].

\section{2 - Métodos}

\subsection{1 - Cromatografia de filtração em gel}

Alíquotas da fração globulina principal foram dissolvidas em tampão fosfato de potássio $10 \mathrm{mM}, \mathrm{pH} 7.5$, contendo $\mathrm{NaCl} 0,5 \mathrm{M}$ e aplicadas em coluna de Sepharose CL-6B $(2,5 \times 100 \mathrm{~cm})$ previamente equilibrada com o mesmo sistema solvente. As proteínas foram eluídas com o mesmo tampão, coletadas frações de $5 \mathrm{~mL}$ cada e feita leitura a $280 \mathrm{~nm}$ para traçar o perfil.

\subsection{2 - Determinação de proteínas}

Proteínas foram determinadas pelo método de LOWRY et al. [25] e por medida de absorvância a 280nm na eluição cromatográfica e por determinação de nitrogênio [3].

\subsection{3 - Estudo de solubilidade}

Os ensaios de solubilidade da globulina purificada e liofilizada foram feitos em função de $\mathrm{pH}$, concentração de $\mathrm{NaCl}, \mathrm{pH}$ e $\mathrm{NaCl}$, tanto na forma nativa quanto após aquecimento a $121^{\circ} \mathrm{C} / 15 \mathrm{~min}$.

\subsection{4 - Eletroforese em gel de poliacrilamida/ poliacrilamida-dodecilsulfato de sódio}

A eletroforese das proteínas nativas e purificadas em condições não-dissociantes foi realizada de acordo com o método descrito por DAVIS [12]. A determinação de número e pesos moleculares das subunidades protéicas foram determinados pelo procedimento descrito por LAEMMLI [24].

\subsection{5 - Determinação de carboidratos}

Os carboidratos das frações protéicas, após precipitação das proteínas com ácido tricloroacético 10\%, foram determinados pelo método fenol-ácido sulfúrico de DUBOIS et al. [16], usando glicose como padrão.

\subsection{6 - Hidrólise enzimática in vitro}

A globulina principal isolada, seguido de separação cromatográfica em gel de Sepharose CL-6B, foi submetida à hidrólise enzimática in vitro com as enzimas tripsina e quimotripsina, separadamente. As soluções de proteínas foram preparadas em tampão fosfato de potássio 20mM, pH 7,8, em concentrações de 1-3mg/mL. Alíquotas foram tomadas, contendo $0,5-1,0 \mathrm{mg}$ de proteína, e adicionado volumes de solução de enzima e estabelecida uma proporção enzima:substrato de 1:10. Para cada ensaio foram preparadas, em triplicata, soluções de enzima-substrato, substrato sem enzima e solução de enzima (controle), em tampão fosfato de potássio $20 \mathrm{mM} \mathrm{pH} 7,8$, seguido de incubação em banho-maria a $37^{\circ} \mathrm{C}$ em tubos individuais selados com parafilme. Esse procedimento foi seguido para diferentes tempos de incubação (15s a $2 \mathrm{~h}$ ), e a cada tempo os tubos selados eram retirados do banho, diluídos dez vezes seu volume com tampão, seguido de armazenamento em banho-de-gelo e imediata determinação da extensão de hidrólise. Para efeito de comparação solução de caseína, nas mesmas condições citadas para as amostras, foram utilizadas como padrão de referência no cálculo da extensão de hidrólise. A hidrólise (grau/ extensão) foi acompanhada pelo doseamento do $\alpha$-amino nitrogênio com ácido trinitrobenzenosulfonico (TNBS) de acordo com o método de FIELDS [17], conforme modificação realizada por SPADARO et al. [37]. As absorvâncias registradas (420nm) com as amostras de enzima e substrato no tempo zero de incubação (início) foram subtraídas dos valores obtidos para as amostras nos diferentes tempos de incubação. Para o cálculo da percentagem de hidrólise foi utilizado o coeficiente de absortividade molar de 16500 para os $\varepsilon$-trinitrofenilderivados, e $113 \mathrm{~g} / \mathrm{Mol}$ como peso molecular médio dos resíduos de aminoácidos nas proteínas. Os cálculos foram expressos para o tempo de 120 minutos de hidrólise.

\subsection{7 - Efeito da temperatura e NaCl na hidróli- se enzimática da globulina principal}

A globulina isolada-liofilizada foi dissolvida em tampão fosfato de potássio 20mM, pH 7,8 (4,0mg/mL), e tampão fosfato de potássio $10 \mathrm{mM}, \mathrm{pH} 7,8$, contendo $0,3 \mathrm{M}$ de $\mathrm{NaCl}(4,0 \mathrm{mg} / \mathrm{mL})$, e feita incubação à temperatura de $4^{\circ} \mathrm{C}$ por $15 \mathrm{~min}$. Após incubação, a concentração de proteína foi ajustada para a hidrólise com a tripsina e quimotripsina $(\mathrm{pH} \mathrm{7,8)}$ conforme descrito acima na ausência de $\mathrm{NaCl}$. Para determinação do efeito de temperatura, soluções de proteína foram preparadas, conforme descrito, aquecidas as temperaturas de 96 e $121,1^{\circ} \mathrm{C} / 15 \mathrm{~min}$, separadamente, seguido de resfriamento, ajuste de concentração de proteína para as hidrólises 
com as enzimas. Para todos ensaios de hidrólise foi utilizada a relação enzima:substrato de 1:10.

\section{3 - RESULTADOS E DISCUSSÃO}

O teor de proteína no grão-de-bico varia entre 12,6 e 30,5\% [9]. A cultivar IAC-Marrocos apresentou teor protéico de 23,99\%, lipídIos 8,6\%, fibra bruta 1,05\% e cinzas $2,73 \%$ situando-se próximo aos valores registrados para variedades cultivadas em diferentes localidades [5, 9, 20]. A globulina principal representou $20,93 \%$ da proteína total da farinha correspondendo a $50 \%$ da globulina total. Quando submetida à eletroforese em gel de poliacrilamida apenas uma banda protéica foi revelada [35]. A eluição da globulina em coluna $(1,7 \times 100 \mathrm{~cm})$ contendo Sephadex G-200 permitiu estimar um peso molecular de $325 \mathrm{kDa}$ e teor de carboidratos de $0,90 \%$ [35]. O peso molecular da fração legumina em diferentes leguminosas situa-se neste intervalo: $350 \mathrm{kDa}$ para Vicia faba, 360kDa para Pisum sativum, $340 \mathrm{kDa}$ para Phaseolus vulgaris, 330kDa para Phaseolus aureus [13] e 375kDa para Lens culinaris [28, 29].

\section{1 - Caracterização das subunidades}

A eletroforese em gel de poliacrilamida contendo dodecilsulfato de sódio (SDS) na ausência de agente redutor mostra a presença de cinco subunidades principais (Figura 1), cujos pesos moleculares situam-se entre $55 \mathrm{kDa}$ e $35,3 \mathrm{kDa}$. Baseado na intensidade de coloração, as bandas com pesos moleculares de 55 e $52,5 \mathrm{kDa}$ parecem ser as principais, seguidas daquelas de média intensidade, com 40,2, 38,5 e 35,3kDa. Essas subunidades quando submetidas ao tratamento com 2-mercaptoetanol tiveram sua ligação dissulfeto reduzida dando origem a quatro bandas protéicas de pesos moleculares na faixa entre 41,2 e $18 \mathrm{kDa}$. As bandas correspondentes aos peptídios de pesos moleculares $41,2,37,5$ e $19,2 \mathrm{kDa}$, apresentaram maior intensidade de coloração e foram seguidas daquelas de 35,3, 20 e $18 \mathrm{kDa}$. Como se observa na Figura 1 as subunidades de pesos moleculares de 55 e $52,5 \mathrm{kDa}$, encontradas somente na ausência do redutor, são constituídas de dois ou mais peptídios unidos por meio de ligações de dissulfeto.

KUMAR \& VENKATARAMAN [23] constataram em gel de poliacrilamida contendo dodecilsulfato de sódio a presença de cinco bandas para a globulina principal, 10,3S do grão-de-bico, com pesos moleculares entre 23 a $98 \mathrm{kDa}$. Segundo os autores as subunidades com pesos moleculares de 52 e $98 \mathrm{kDa}$ podem aparecer como artefatos produzidos pela formação de ligações de dissulfeto entre grupos sulfidrilas pareados, resultante da exposição ao agente dissociante. Os autores verificaram que a globulina 10,3S apresenta no mínimo três ligações de dissulfeto, o que explica parcialmente a estrutura não compacta dessa proteína.

VAIRINHOS \& MURRAY [39], no estudo de Cicer arietinum, C. reticulatum e C. echinospermun, verificaram que a globulina da espécie $C$. arietinum é constituída de seis polipeptídios, os quais são unidos por ligações de dissulfeto compostos por subunidades de 41, 39, 36, $31,22,21$ e $14 \mathrm{kDa}$.

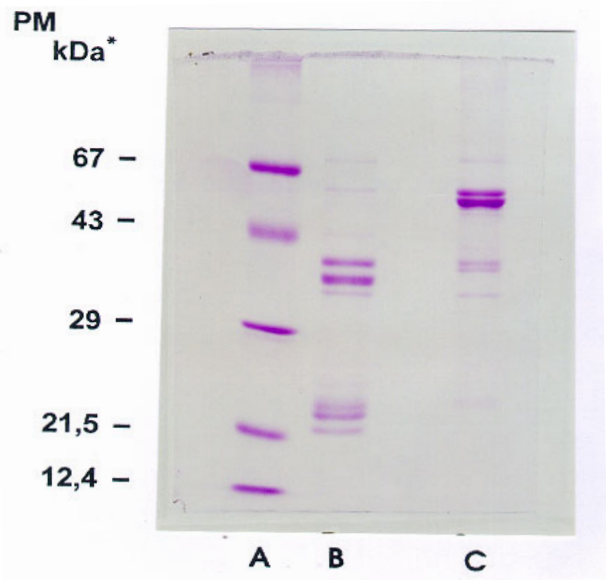

FIGURA 1. Eletroforese da globulina principal do grão-debico em gel de poliacrilamida-dodecilsulfato de sódio (SDS), na presença (B) e ausência (C) do agente redutor 2-mercaptoetanol, realizada de acordo com o método de LAEMMLI [24]. (A) Padrão de pesos moleculares.

\section{2 - Solubilidade da globulina principal}

A Figura 2 mostra o perfil de solubilidade da globulina principal após cromatografia em Sepharose CL-6B. A solubilização iniciou-se entre 0,05 e 0,1M de $\mathrm{NaCl}$ e alcançou $80 \%$ de solubilidade a partir de $0,8 \mathrm{M}$. Observa-se, na Figura 3, uma curva típica de solubilidade de globulinas com valores máximos a pHs 2,0 e acima de 8,0. A adição de sais neutros em quantidades crescentes tende a modificar a interação eletrostática das moléculas em solução e a diferentes valores de pHs. Adição de $\mathrm{NaCl} 0,2 \mathrm{M}$ levou a um aumento de solubilidade na faixa dos pHs 4,5 a 6,0. Na concentração de 0,5 e 1,0M praticamente não foi afetada a solubilidade da proteína acima do $\mathrm{pH} 4,5$, entretanto, reduziuse nos pHs inferiores a 4. NEVES [28] verificou que a fração G1 de Lens esculenta apresenta-se insolúvel na faixa de $\mathrm{pH} 4,0$ a 5,5, alcançando o máximo no $\mathrm{pH} 10$. Adição de sal a 0,5 e 1,0M acentuou a redução de solubilidade nos pHs inferiores a $\mathrm{pH} 4,0$.

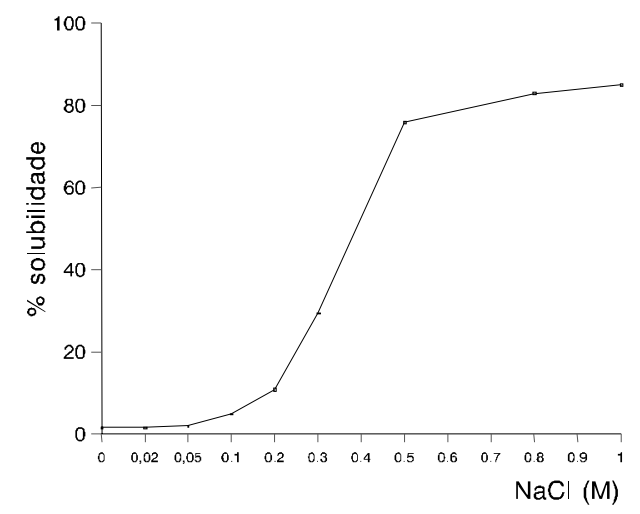

FIGURA 2. Efeito da concentração de $\mathrm{NaCl}$ na solubilidade da globulina principal de grão-de-bico, cultivar IAC-Marrocos. Determinação pelo método de LOWRY et al. [25]. 


\section{3 - Hidrólise enzimática in vitro: efeito de aque- cimento e $\mathrm{NaCl}$}

Na relação enzima:substrato de 1:10, a globulina nativa apresentou grau de hidrólise inferior à caseína e o aquecimento a $96^{\circ} \mathrm{C}$ e $121,1^{\circ} \mathrm{C} / 15 \mathrm{~min}$. não foram suficientes para hidrólise total, por ambas enzimas ( $\mathrm{Ta}-$ bela 1). É importante ressaltar que as proteínas encontram-se em tampão fosfato de potássio $20 \mathrm{mM}$, pH 7,8 e na ausência de sal. A redução na hidrólise da globulina principal pela presença de $\mathrm{NaCl} 0,3 \mathrm{M}$ foi substancial, alcançando $48,7 \%$ e $52,8 \%$ da caseína (100\%) para tripsina e quimotripsina, respectivamente. O aquecimento na presença do sal reduziu sua susceptibilidade à ação enzimática, embora em menor grau (Tabela 1).
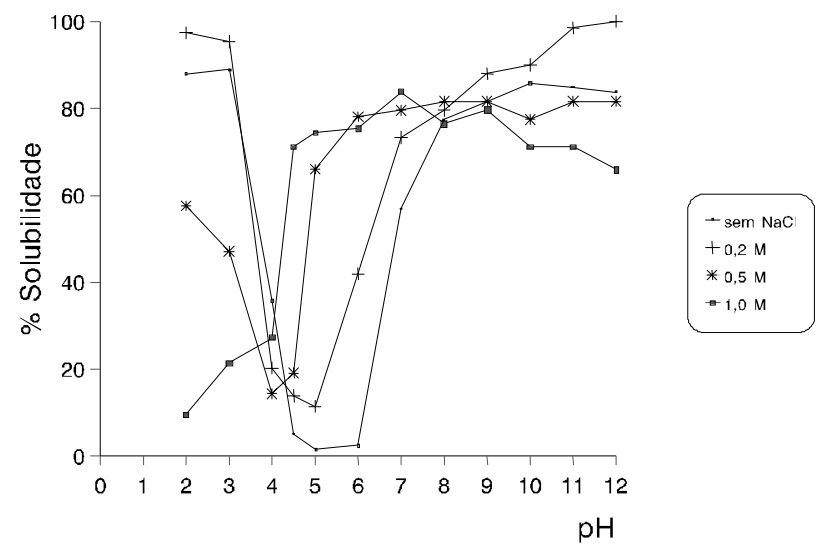

FIGURA 3. Efeitos do pH e concentração de $\mathrm{NaCl}$ na solubilidade da globulina principal de grão-de-bico, cultivar IAC-Marrocos. Os pHs foram ajustados com $\mathrm{NaOH}$ ou $\mathrm{HCl}$ e a proteína quantificada pelo método de LOWRY et al. [25].

TABElA 1. Percentual de hidrólise da globulina principal de grão-de-bico frente à tripsina e quimotripsina

\begin{tabular}{lccc}
\hline \multirow{1}{*}{ ENZIMA } & \multicolumn{3}{c}{$\begin{array}{c}\text { GLOBULINA PRINCIPAL } \\
(\% \text { hidrólise })^{*}\end{array}$} \\
\cline { 2 - 4 } TRIPSINA & NATIVA & $96^{\circ} \mathrm{C} / 15 \mathrm{~min}$ & $121,1^{\circ} \mathrm{C} / 15 \mathrm{~min}$ \\
Ausência de sal & $73,3 \pm 1,3$ & $82,0 \pm 1,4$ & $89,7 \pm 2,3$ \\
NaCI 0,3 M & $48,7 \pm 2,1$ & $74,0 \pm 1,9$ & $83,6 \pm 1,2$ \\
QUIMOTRIPSINA & & & \\
Ausência de sal & $80,0 \pm 1,8$ & $88,5 \pm 1,7$ & $84,5 \pm 1,9$ \\
NaCI 0,3 M & $52,8 \pm 2,5$ & $52,7 \pm 2,4$ & $77,2 \pm 1,8$ \\
\hline
\end{tabular}

*valores representando a média de ensaios em triplicata

**em relação à caseína (100\%).

O progresso da hidrólise tríptica com o tempo pode ser observado em eletroforese em gel de poliacrilamidadodecilsulfato de sódio nas Figuras 4 e 5 . Na presença de 2-mercaptoetanol observa-se maior resistência dos polipeptídeos na faixa de 21,5 a 35kDa, especialmente na faixa inferior, até 60 minutos de hidrólise.
(A)

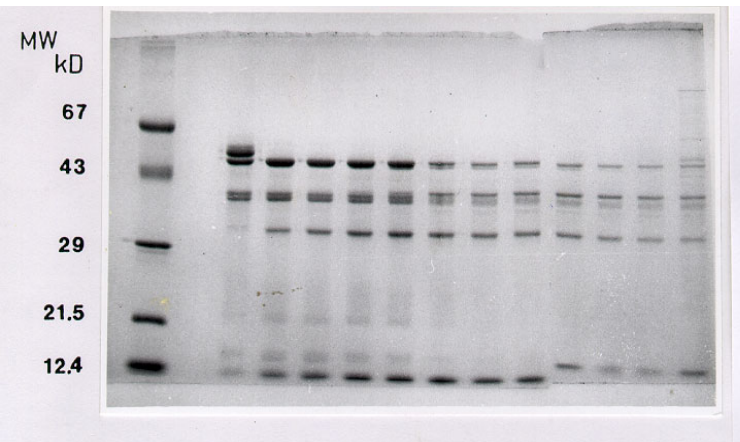

(B)

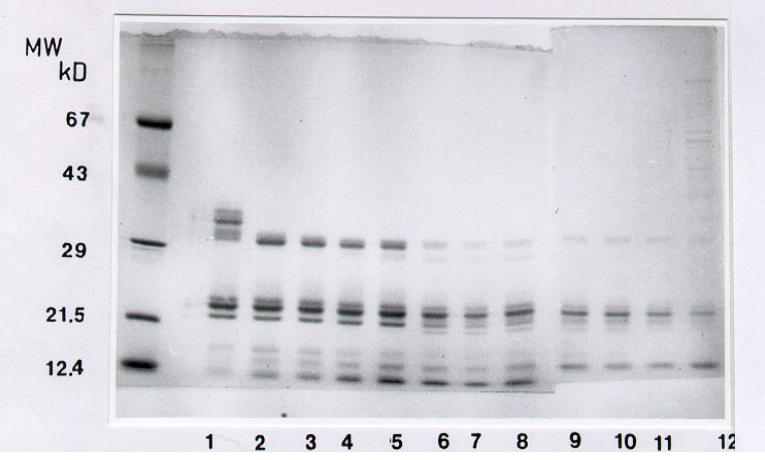

FIGURA 4. Eletroforese em gel de poliacrilamida dodecilsulfato de sódio dos produtos de hidrólise da globulina principal de grão-de-bico com a tripsina na ausência de NaCl. Relação enzima:substrato, 1:10. Tempos: 0, 15, 30seg, 1, 2, 15, 30 e 60min.,3, 6, 12 e 24h. (A) sem, (B) com 2-mercaptoetanol.

(A)

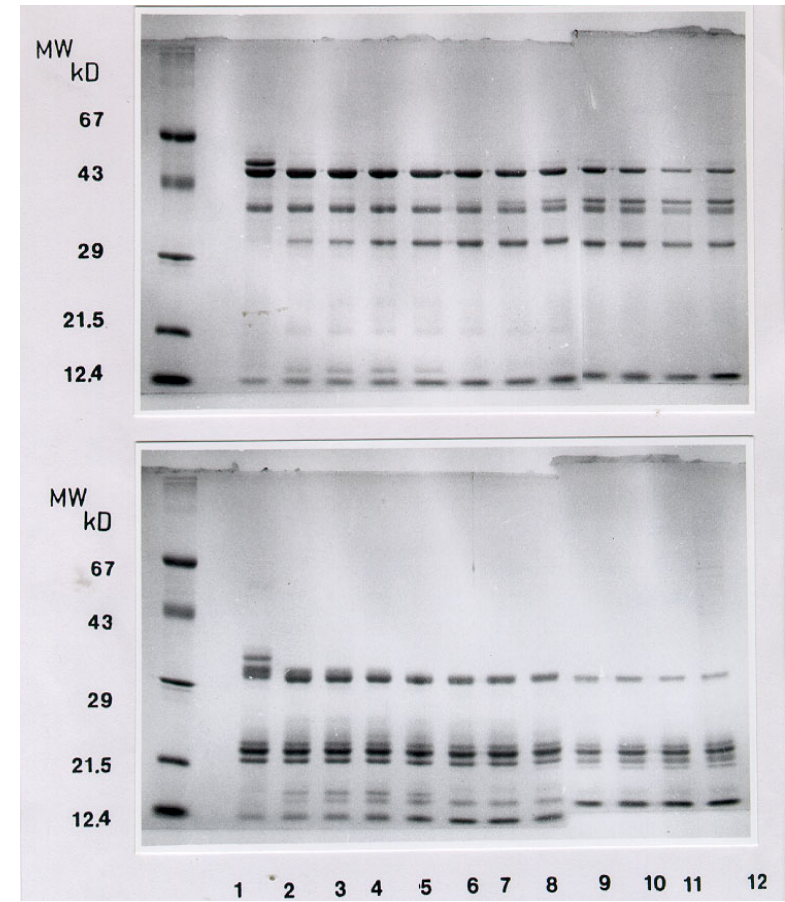

FIGURA 5. Eletroforese em gel de poliacrilamida dodecilsulfato de sódio dos produtos de hidrólise da globulina majoritária de grão-de-bico com a tripsina na presença de 0,3M de NaCl. Relação enzima:substrato, 1:10. Tempos: 0, 15, 30seg, 1, 2, 15, 30 e 60min.,3, 6, 12 e 24h. (A) sem, (B) com 2-mercaptoetanol. 
Na ausência de redutor, confirma-se o aumento de intensidade de uma banda correspondente a um novo polipeptídio $(32 \mathrm{kDa})$, concomitante à rápida redução daquele de $55 \mathrm{kDa}$, indicando a possibilidade de resultar de um produto modificado de sua hidrólise ou mesmo da redução do componente mais resistente de $52,5 \mathrm{kDa}$. No entanto, parece provável que o polipeptídio de $55 \mathrm{kDa}$ produza, por redução, cadeias próximas a $30 \mathrm{kDa}$, seguido de degradação rápida a componentes menores entre 20 e $30 \mathrm{kDa}$ bem como entre 12 e $20 \mathrm{kDa}$.

A Figura 5 mostra o efeito de $\mathrm{NaCl}$ 0,3M na hidrólise pela tripsina, confirmando o observado pela reação com o ácido trinitrobenzenosulfonico (TNBS). As figuras demonstram que a globulina apresentou-se resistente mesmo após 24 horas de hidrólise, e que na presença de sal ainda permaneciam subunidades na faixa de $30 \mathrm{kDa}$.

A globulina foi progressivamente hidrolisada, na ausência de $\mathrm{NaCl}$, após 3 horas e até 24 horas de exposição à quimotripsina (Figura 6), no entanto o mesmo não ocorreu na presença do sal (Figura 7). Essas observações confirmam o mesmo efeito observado com a tripsina, no entanto possiveis reações de agregação entre produtos da hidrólise parecem ter ocorrido neste caso, observando-se o surgimento de frações com maior peso molecular, após uma hora de hidrólise, um fato não observado na ausência de sal.
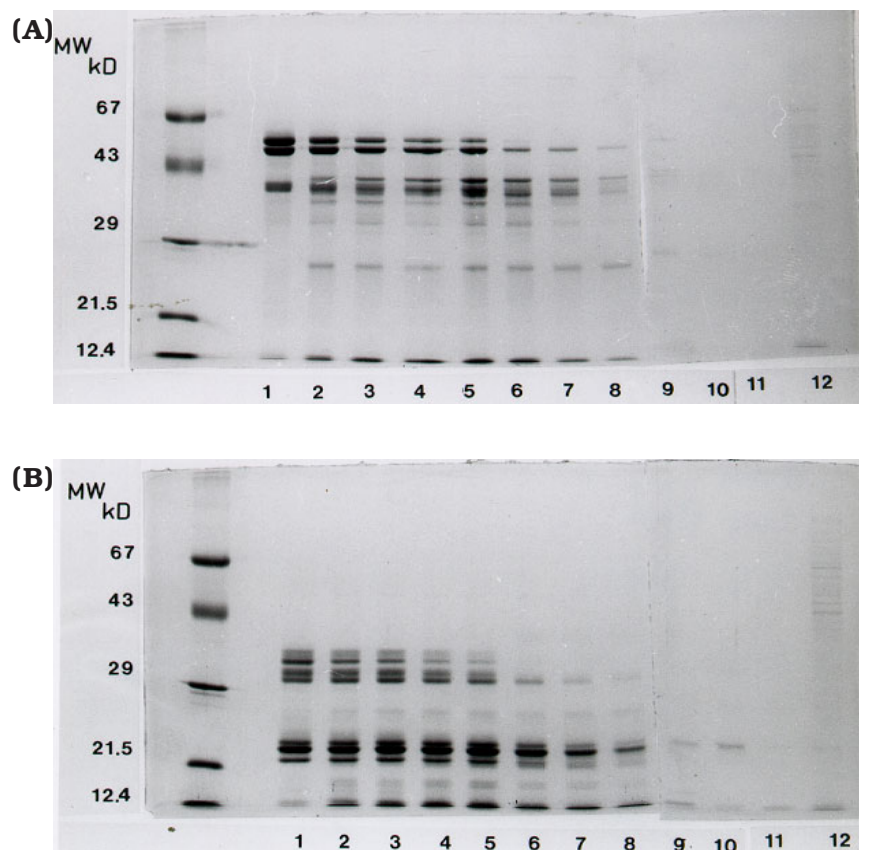

FIGURA 6. Eletroforese em gel de poliacrilamida dodecilsulfato de sódio dos produtos de hidrólise da globulina principal de grão-de-bico com a quimotripsina na ausência de $\mathrm{NaCl}$. Relação enzima:substrato, 1:10. Tempos: 0, 15, 30seg, 1, 2, 15, 30 e 60min.,3, 6, 12 e 24h. (A) sem, (B) com 2-mercaptoetanol.

Inúmeros estudos evidenciam o efeito da força iônica no processo de associação-dissociação das fra- ções legumina (11S) e vicilina (7S) em leguminosas, e embora grande parte dos trabalhos tenham se concentrado na fração 7S de feijão, ervilha e soja, apontam dependência das características estruturais de cada proteína [6, 14, 15, 22, 30, 31]. Esse efeito de redução na susceptibilidade proteolítica da globulina de grãode-bico em função de aumento da força iônica é resultado de provável estabilidade conformacional das cadeias, conferida pelo sal, conforme já observado para globulinas $7 \mathrm{~S}[14,30,33]$ e $11 \mathrm{~S}[18,30,32]$ de outras espécies.
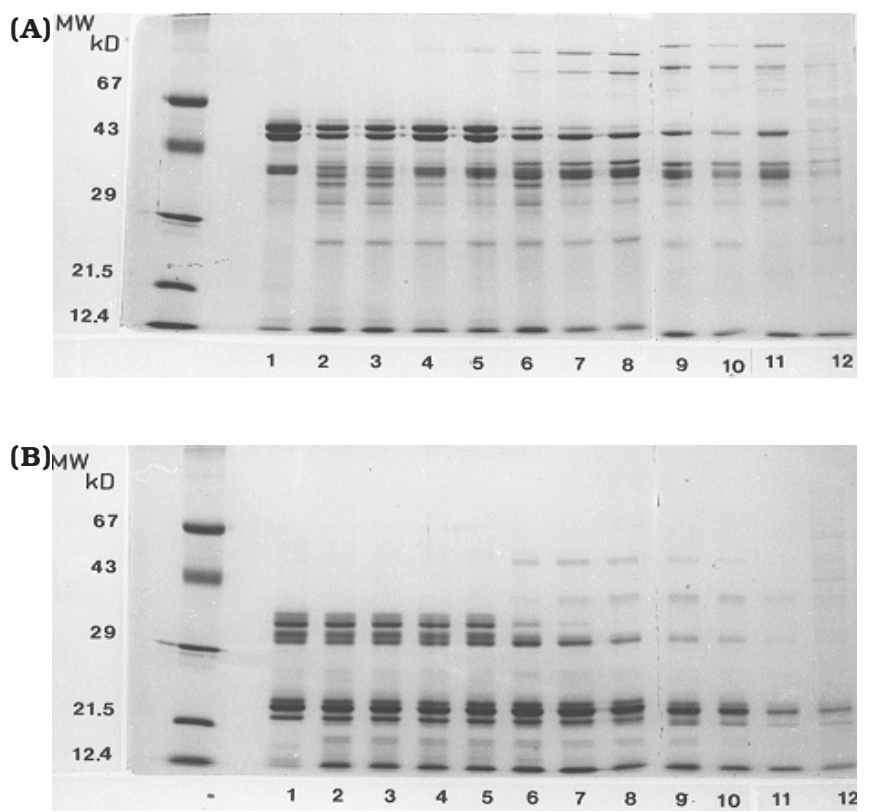

FIGURA 7. Eletroforese em gel de poliacrilamida dodecilsulfato de sódio dos produtos de hidrólise da globulina principal de grão-de-bico com a quimotripsina na presença de $\mathrm{NaCl}$ 0,3M. Relação enzima:substrato, 1:10. Tempos: 0, 15, 30seg, 1, 2, 15, 30 e 60min.,3, 6, 12 e 24h. (A) sem, (B) com 2-mercaptoetanol.

KELLA, BARBEAU \& KINSELLA [21] observaram diferentes susceptibilidades trípticas para a glicinina e seus polipeptídios ácidos e básicos, sendo os primeiros mais susceptíveis à enzima. Os autores verificaram que o rompimento de pontes dissulfeto facilitava a proteólise da glicinina e polipeptídios ácidos, reduzindo a dos básicos, o que sugere possiveis reações de agregação entre os últimos como responsáveis pela menor susceptibilidade as proteases. Esse comportamento mostra-se como uma característica das frações $1 \mathrm{~S}$, pois a resistência à tripsinólise da legumina-T de ervilha é explicada por PLUMB et al. [32] pela influência de interações hidrofóbicas favorecidas pelo aumento da concentração salina. Dessa forma, a homologia estrutural entre globulinas 11S de diferentes espécies parece influenciar o seu comportamento frente às proteases, pois os estudos indicam que a tripsina age sobre a região C-terminal da molécula com características ácidas e na sua superfície, contrário à região $\mathrm{N}$ - 
terminal sem a presença de grupos ácidos e situadas no seu interior $[21,32]$.

\section{4 - CONCLUSÕES}

A globulina majoritária de grão-de-bico de peso molecular de $325 \mathrm{kDa}$ revelou ao menos 5 subunidades na faixa de 55 a $35 \mathrm{kDa}$. A proteína isolada e purificada apresentou características de solubilidade típicas de proteína com estrutura compacta. Os resultados da hidrólise in vitro indicam que a globulina principal de grão-de-bico na forma nativa mostrou-se resistente à tripsina e quimotripsina, nas condições testadas, e os efeitos do aquecimento não foram suficientes para aumentar a hidrólise da proteína comparado ao obtido com a caseína. A presença de $\mathrm{NaCl} 0,3 \mathrm{M}$ alterou a estabilidade conformacional da proteína, acarretando em redução da susceptibilidade proteolítica da sua forma nativa, em maior, e das aquecidas, em menor grau.

\section{5 - REFERÊNCIAS BIBLIOGRÁFICAS}

[1] AHN, J.K.; SEM, L.C.; WHITAKER, J.R. Stability of tertiary structure of phaseolin of red kidney bean (Phaseolus vulgaris) as limiting factor in proteolysis. Journal Food Biochemistry; v.15, p.263-78, 1991.

[2] AKMAL-KHAN, M.; NEGHMANA, A.; IHSAN, U.; SAEEDA, J. Nutritional evaluation of desi and kabuli chickpeas and their products commonly consumed in Pakistan. International Journal of Food Science and Nutrition, v.46, p.215-23, 1995.

[3] ASSOCIATION OF OFFICIAL ANALYTICAL CHEMISTS. Official Methods of Analysis, $13^{\text {th }}$ ed., Washington, D.C., 1980.

[4] ATTIA, R.S.; El-TABEY SHEHATA, A..M.; AMAN, M.E.; HAMZA, M.A. Effect of cooking and decortication on the physical properties, the chemical composition and the nutritive value of chickpea (Cicer arietinum L.). Food Chemistry, v.50, p.125-31, 1994.

[5] AVANCINI, S.R.P.; SAlES, A.M.; AGUIRRE, J.M.; MANTOVANI, D.M.B. Composição química e valor nutricional de cultivares de grão-de-bico produzidos no Estado de São Paulo. Coletânea do ITAL, v.22, p. 14553, 1992.

[6] BRADBEAR, N.; BOULTER, D. The use of enzyme hydrolysis of in vitro to study the digestibility of some Phaseolus seed proteins. Qualitas Plantarum Plant Foods Human Nutrition, v.34:, p.3-13, 1984.

[7] CARBONARO, M.; CAPPELlONI, M.; NICOLI, S., LUCARINI, M.; CARNOVALE, E. Solubility-digestibility relationship of legume proteins. Journal of Agricultural Food Chemistry, v.45, p.3387-94, 1997.

[8] CHAVAN, J.K.; DJURTOFT, R. Purification and characterization of seed globulins from black gram (Phaseolus mungo). Journal Science Food Agriculture;v.33, p. 471-80, 1982.

[9] CHAVAN, J.K.; KADAM, S.S.; SALUNKE, D.K. Biochemistry and technology of chickpea (Cicer arietinum L.) seeds. CRC-Critical Review of Food Science and Nutrition, v. 25, p.107-158, 1986

[10] ChITRA, U.; VIMALA, V.; SINGH, U.; GEERVANI, P. Variability in phitic acid content and protein digestibility of grain legumes. Plant Foods for Human Nutrition, v.47, p. 163-72, 1995.
[11] CLEMENTE, A.; SANCHES-VIOQUE, R.; VIOQUE, J.; BAUTISTA, J.; MILLAN, F. Effect of cooking on protein quality of chickpea (Cicer arietinum L.). Food Chemistry, v.62, p.1-6, 1998.

[12] DAVIS, B.J. Disc electrophoresis II - Method and application to human serum proteins. Annals of the New York Academy of Science, v.121, p. 404-27, 1964.

[13] DERBYSHIRE, E.; WRIGHT, D.J.; BOULTER, D. Review - Legumin and vicilin, storage proteins of legume seeds. Phytochemistry, v. 15, p.3-24, 1976

[14] DESHPANDE, S.S.; DAMODARAN, S. Structure digestibility relationship of legume $7 \mathrm{~S}$ e protein. Journal of Food Science, v.54, p.108-13, 1989.

[15] DESHPANDE, S.S.; NIELSEN, S.S. In vitro digestibility of dry beans (Phaseolus vulgaris L.) proteins: the role of heat-stable protease inhibitors. Journal of Food Science, v.52, p. 1330-34, 1987c.

[16] DUBOIS, M.; GILLES, K.A.; HAMILTON, J. K.; REBERS, P. A.; SMITH, F. Colorimetric method for determination of sugars and related substances. Analytical Chemistry, v.28, p. 1350-56, 1956.

[17] FIELDS, R. The rapid determination of aminogroups with TNBS. Methods in Enzimology; v.25, p. 464$68,1972$.

[18] GUEGUEN, J.; CHEVAlier, M.; BARBOT, J.; SCHAEFFER, F. Dissociation and agregation of pea legumin induced by $\mathrm{pH}$ and ionic strenght. Journal of Science and Food Agriculture, v.44, p.167-82, 1988.

[19] JACKSON, P.; BOUlTER, D.; THURMAN, D.A. A comparison of some properties of vicilin and legumin isolated from seeds of Pisum sativum, Vicia faba and Cicer arietinum. New Phytology, v.68, p. 25-33, 1969.

[20] KBALEgUE, A.; ElÍAS, L. G.; BRAHAM, J.E.; BRESSANI. R. Studies on the development of infant foods from plant protein sources. Part I. Effect of germination of chickpea (Cicer arietinum) on the nutritive value and digestibility of proteins. Archivos Latinoamericanos de Nutricion, v.35, p. 315-25, 1985.

[21] KELLA, N.K.D.; BARBEAU, W.E.; KINSELLA, J.E. Effect of oxidative sulfitolysis of dissulfide bonds of glycinin on solubility, surface hydrophobicity and in vitro digestibility. Journal Agriculture of Food Chemistry, v.34, p. 251-56, 1986.

[22] KOSHIYAMA, I. Comparison of acid-induced conformation changes between 7S and 11S globulins in soybean seds. Journal of Science and Food Agriculture,.23: 853-59, 1972.

[23] KUMAR, K.G.; VENKATARAMAN, L.V. Chickpea seed proteins: Isolation and characterization of $10.3 \mathrm{~S}$ protein. Journal of Agriculture and Food Chemistry, v.28, p. 524-29, 1980.

[24] LAEMMLI, U.K. Cleavage of structural proteins during the assembly of the head of bacteriophage T4. Nature, v. 227 , p. $680-84,1970$.

[25] LOWRY, O. H.; ROSEBROUGH, N. J.; FARR, L. A.; RANDALL, R. J. Protein measurement with the Folin phenol reagent. Joural of Biological Chemistry, v.193, p. 265-75, 1951.

[26] MENDEZ, M.H.; DERIVI, S.C.; FERNANDES, M.L.; OLIVEIRA, A.M. Insoluble dietary fiber of grain food legumes and protein digestibility. Archivos Latinoamericanos de Nutricion, v.43, p.66-72, 1993.

[27] NESTARES, T.; LOPEZ-FRIAS, M.; BARRIONUEVO, M.; URBANO, G. Nutritional assessment of raw and processed chickpea (Cicer arietinum $\mathrm{L}$ ) protein in growing 
rats. Journal of Agriculture and Food Chemistry, v.44, p. 2760-65, 1996.

[28] NEVES, V.A. Isolamento e digestibilidade in vitro da proteína da lentilha (Lens esculenta). São Paulo, 1991. 140 p. Tese de doutorado (Doutor em Ciência de Alimentos) - Faculdade de Ciências Farmacêuticas, Universidade de São Paulo (USP).

[29] NEVES, V.A.; LOURENÇO, E.J. Isolation and in vitro hydrolysis of globulin G 1 from lentils (Lens culinaris, Medik). Journal of Food Biochemistry, v.19, p. 10920, 1995.

[30] NIELSEN, S.S. Degradation of bean proteins by endogenous and exogenous proteases. A Review. Cereal Chemistry, v. 65, p.435-42, 1988.

[31] NIELSEN, S.S.; DESHPANDE, S.S.; HERMODSON, M.A.; SCOTT, M.P. Comparative digestibility of legume storage proteins. Journal of Agriculture and Food Chemistry, v.36, p.896-902, 1988.

[32] PLUMB, G.W.; CARR, H.J.; NEWBY, V.K.; LAMBERT, N. A study of trypsinolysis of pea $11 \mathrm{~S}$ globulin. Biochim. Biophys. Acta.; v. 999, p. 281-88, 1988.

[33] SATHE, S.K.; IDOURAINE, A.; WEBER, C. W. Purification and biochemical characterization of tepary bean (Phaseolus acutifolius) major globulin. Food Chemistry, v.50, p. 261-66, 1994.

[34] SAYEED, S.; NJAA, L.R. Effect of a Bangladeshi home coooking procedure on the amino acid content, trypsin inhibitor activity and in vitro digestibility of some legume seeds. Qualitas Plantarum Plant Foods Human Nutrition, v.35, p.379-88, 1985.

[35] SILVA, M.A.; NEVES, V.A.; LOURENÇO, E.J. Frações protéicas e globulina principal de grão-de-bico (Cicer arietinum L.), cv IAC - Marrocos. Alimentos e Nutrição, v.12, p.131-149, 2001.
[36] SINGH, U. Nutritional quality of chickpea (Cicer arietinum L.): current status and future research needs. Qualitas Plantarum Plant Foods Human Nutrition, v.35, p. 339-51, 1985.

[37] SPADARO, A.C.C.; DRAGHETTA, W.; DEL LAMA, S.N.; CAMARGO, A.C.M.; GREEN, L.T. A convenient manual trinitrobenzenesulfonic acid method for monitoring amino acids and peptides in chromatographic column effluents. Analytical Biochemistry, v.96, p.317-21, 1979.

[38] SUN, S.M.; HALL, T.C. Solubility characteristics of globulins from Phaseolus seeds in regard to their isolation and characterization. Journal of Agricultural and Food Chemistry,v.23, p.184-89, 1975.

[39] VAIRINHOS, F.; MURRAY, D.R. The seed proteins of chickpea: Comparative studies of Cicer arietinum, C. reticulatum and C. echinospermum (Leguminosae). Plant Systematic Evolution, v.142, p.11-22, 1983.

[40] WRIGHT, D. J.; BOULTER, D. Purification and subunit structure of legumin of Vicia faba L. (Broad bean). Biochemical Journal, v.141, p.413-18, 1974.

\section{6 - AGRADECIMENTOS}

À FAPESP (Fundação de Amparo à Pesquisa do Estado de S. Paulo, processo 94/1100-6) e PADC-FCFUNESP (Programa de Apoio ao Desenvolvimento Científico da Faculdade de Ciências Farmacêuticas da Universidade Estadual Paulista-UNESP). 